\title{
Cross-Cultural Evidence for Spatial Bias in Beliefs About the Severity of Environmental Problems
}

P. Wesley Schultz ${ }^{1}$, Taciano L. Milfont ${ }^{2}$, Randie C. Chance ${ }^{3}$, Giuseppe Tronu $^{4}$, Sílvia Luís ${ }^{5}$, Kaori Ando ${ }^{6}$, Faiz Rasool ${ }^{7}$, Pamela Linera Roose ${ }^{8}$, Charles Adedayo Ogunbode ${ }^{9}$, Juana Castro ${ }^{10}$, and Valdiney V. Gouveia ${ }^{11}$

${ }^{1}$ California State University, San Marcos, USA ${ }^{2}$ Victoria University of Wellington, New Zealand ${ }^{3}$ University of Southern Illinois, Carbondale, USA ${ }^{4}$ Sapienza University of Rome, Italy ${ }^{5}$ Évora University, Portugal ${ }^{6}$ Nara Women's University, Japan ${ }^{7}$ University of Karachi, Pakistan ${ }^{8}$ Universidad Empresarial Siglo 21, Córdoba, Argentina ${ }^{9}$ University of Ibadan, Nigeria ${ }^{10}$ Universidad de Los Andes, Bogota, Colombia ${ }^{11}$ Federal University of Paraiba, Joao Pessoa, Brazil

\section{Corresponding Author:}

P.Wesley Schultz, Department of Psychology, California State University, San Marcos, CA 92078, USA.

Email: wschultz@csusm.edu

\section{Keywords}

spatial bias, spatial optimism, environmental hyperopia, crosscultural research, psychological universals, multilevel modeling 


\begin{abstract}
Prior research has shown a tendency for environmental problems to be rated as more severe at the global level than at the local level. The present article reports reanalyses of a large crosscultural data set (Study 1: $k=22, N=3,277$ ) and new crosscultural data (Study 2: $k=8, N=1,131$ ) examining the prevalence of this spatial bias in the rated severity of environmental problems along with analyses of individual and country-level predictors of this bias. Results from multilevel modeling analyses showed that spatial bias was greater for happier and younger individuals and for those from smaller communities. We interpret these results as evidence for selfserving and "place-serving" biases in which the bias tempers the severity of environmental problems in one's local area. Considering the large cross-cultural evidence, we argue that spatial bias is a plausible candidate of a psychological universal identified by research in environmental psychology.
\end{abstract}


Environmental problems pose serious threats to life across the planet. These issues transcend national and even continental boundaries, and lend themselves to a cross-cultural perspective (Dunlap, Gallup, \& Gallup, 1993; Milfont, 2012; Schultz \& Zelezny, 1999).

Cross-cultural surveys have shown that laypeople recognize the impact of human behavior on global environmental changes and that individuals are generally willing to act to protect the environment. However, research has also shown that individuals view environmental risks as more likely to happen elsewhere and to other people than in the local area and to oneself (e.g., Dunlap et al., 1993; Fleury-Bahi, 2008; Hatfield \& Job, 2001; Lima \& Castro, 2005; Pahl, Harris, Todd, \& Rutter, 2005; Uzzell, 2000). This belief that environmental risks are more likely elsewhere is an unrealistic perception of environmental conditions given the interdependence of natural systems. At the same time, this unrealistic and biased perception of environmental conditions is also pervasive and likely to function as a barrier for individuals to address local environmental problems.

In the psychological literature, this unrealistic perception of global environmental problems as more severe than local environmental problems has been called "environmental hyperopia” (Uzzell, 2000) and more recently "spatial optimism” (Gifford et al., 2009). Although spatial bias has been reported in several recent publications, there are a number of important questions that remain to be addressed. The current work builds on a previous study by Gifford and colleagues (2009) with new cross-cultural data. The goals of the present research were threefold. The first goal was to replicate Gifford et al.'s finding for spatial bias in a cross-cultural data set. The second goal was to test three possible explanations for spatial bias by testing hypotheses at the individual level and country levels through multilevel modeling. The third goal was to examine whether the differences in perceptions of environmental problems at the local and global levels are accurate, or indeed biased. We start with a review of spatial bias and follow with three possible explanations of this bias. Two 
cross-cultural data sets are then used to test these explanations.

\section{Understanding Spatial Bias}

Spatial bias refers to an individual's tendency to incorrectly assess global environmental conditions as worse than local conditions. Interestingly, researchers have consistently found that individuals around the world, both from industrial and nonindustrial countries, see environmental conditions as being adversely affected by human activity, and they see environmentalconditions deteriorating over time. However, when focusing on their local area, the perceived gravity of these problems is lower than those of the global level (e.g., Dunlap et al., 1993; Gifford et al., 2009; Hatfield \& Job, 2001; Jianguang, 1994; Marques, Palma-Oliveira, Marques, \& Ferreira, 1995; Milfont, Abrahamse, \& McCarthy, 2011; Milfont, Sibley, \& Duckitt, 2010; Palma-Oliveira, 2001; Uzzell, 2000). For instance, in their cross-cultural investigation, Gifford and colleagues (2009) found that assessments of environmental conditions generally decreased as spatial distance increased (my area, my country, globally). Samples from 15 out of the 18 countries included in their study reported that environmental conditions (such as air quality, biodiversity, water, and traffic) were better in their area than in their country, and that the country's conditions, in turn, were better than global ones.

Although acknowledgment of spatial bias is not new (Musson, 1974), researchers have only recently begun to explore this effect more systematically (Uzzell, 2000). In fact, environmental deprivation theory would suggest that greater environmental concern is linked to greater exposure to pollution and environmental degradation (Inglehart, 1995; Tremblay \& Dunlap, 1978); so spatial bias runs contrary to early proposals that individuals would only be concerned about environmental problems to the extent that they were concrete, immediate, and local (e.g., De Haven Smith, 1988). Indeed, spatial bias suggests that individuals can and do relate to impersonal, indirect, and long- term problems like the destruction of the ozone layer or global climate change. 
Furthermore, there appears to be a bias in this direction. Individuals appear to be more concerned about such problems at a global and international level than they are at the local or regional level, a result shared by people with different levels of knowledge, commitment, and interest, and from countries with different degrees of environmental degradation.

Unfortunately, Uzzell (2000) also reported that perceived individual responsibility for responding to environmental problems decreases as the distance increases. Although people feel that they are responsible for the environment at a local level, this is the level at which they perceive the lowest severity of problems. Ironically, the spatial level with the most seriously perceived environmental problems are those where people feel least personally responsible and generally powerless to influence. These findings are important because environmental psychological theories that explore awareness of consequences and ascription of responsibility for environmental problems do not distinguish between different spatial levels (e.g., Stern, Dietz, \& Kalof, 1993).

\section{Predictors of Environmental Spatial Bias}

Although previous studies have documented the tendency for environmental spatial bias, no cross-cultural studies have provided theoretically driven explanations for the effect. Here, we highlight three potential explanations for spatial bias.

Place-serving bias. Environmental spatial bias could be the result of bias in perceptions of a valued place. Prior research has shown that individuals actively strive to maintain a positive place identity (Hugh-Jones \& Madill, 2009). If there is a serious environmental problem in a place with which an individual closely identifies, the person may have a tendency to discount this problem. Hatfield and Job (2001) have shown that optimism bias exists in environmental perceptions. For example, individuals tend to believe that negative environ- mental events are less likely to happen to their local community than to another location. Similarly, individuals believed that they knew more about preventing environmental hazards than their peers. 
Importantly, health studies have also illustrated that optimism bias relates directly with perceived control (Klein \& HelwegLarsen, 2002). Supporting this controllability account in the case of environmental assessments, Pahl and colleagues (2005) found that people did not display optimism bias when they were asked to make risk assessments in case of a hypothetical accident, over which they have no control.

Self-serving bias and happiness. A second potential explanation for spatial bias derives from recent studies of motivated social cognition. A sizablevolume of research has shown that individuals tend to view themselves as possessing more favorable qualities, and less unfavorable qualities, than the average person (Baumeister, 1999). This effect is quite robust and extends to a range of personal qualities, including perceptions about future outcomes (Weinstein, 1980), and even to one's name, pet, and objects that one possesses (the "mere ownership effect”; Barone, Shimp, \& Sprott, 1997;

Gawronski, Bodenhausen, \& Becker, 2007). Self-serving explanations are useful because such perceptual biases help individuals to maintain a positive view of self, and they generally result from inflated views of self rather than deflated views of others (Epley \& Dunning, 2000; Epley \& Whitchurch, 2008). Researchers have also found a robust and widespread optimism bias concerning personal risks (Weinstein, 1989), whereby individuals think that their personal risk is less than that of their peers and subsequently resist efforts to encourage risk- reducing behaviors.

From the self-serving and motivated social cognition perspective, environmental spatial bias is reflective of more general biased perceptions of self, and we speculate that happiness can influence this effect. Research has shown that positive moods influence different approaches to information processing (Fredrickson \& Joiner, 2002). Individuals in a positive mood are more cognitively flexible in categorizing objects (Murray, Sujan, Hirt, \& Sujan, 1990), and thus better able to make fine distinctions when comparing or contrasting objects. Individuals in a positive mood are also more attentive 
to positive information in the environment, and thus more likely to find information that reinforces positive moods (Tamir \& Robinson, 2007) and to transform mood- threatening tasks into mood-benefiting tasks (Hirt, Devers, \& McCrea, 2008). Increased cognitive flexibility and attention to positive information led by positive mood means happy individuals are more likely to find positivity in their environment and more flexible when processing information required for self-serving perceptions. Based on this evidence that positive mood increases self-serving biases, we predict that environmental spatial bias is greater for individuals reporting greater happiness levels.

Knowledge and media exposure. Finally, a third explanation for the spatial bias effect draws on communication channels and media exposure. As Uzzell (2000) questioned, "Is it that mass media coverage, the growth of environ- mental organizations and government interest in the environment has sensitized the public more effectively to global environmental issues than to local ones?” (p. 309). Hatfield and Job (2001) also suggested that the slogan "think globally, act locally" may be misguided because thinking globally about existing problems may cause people not to accept personal vulnerability, and ultimately to inhibit proenvironmental behavior (see also Rabinovich, Morton, Postmes, \& Verplanken, 2009). Likewise, the crosscultural study by Gifford and colleagues (2009) offers the possibility that optimistic spatial bias related to environmental conditions may be a consequence of media reports that have increased awareness and concern about global environmental problems, presuming that coverage of global problems exceeds that of local problems. They provide an accuracy explanation for their findings by arguing that the decreasing negative assessment of environmental conditions from proximate to more distal spatial levels could be accounted for in part by participant accuracy due to media exposure. In line with these arguments, we predict that spatial bias will be greater for participants with greater knowledge about environmental issues. In addition, we predict that spatial bias will be stronger 
in countries with greater levels of media exposure.

\section{Current Research}

This article reports two cross-cultural studies to further explore spatial bias in environmental perceptions. We predict that spatial bias will be greater for participants with stronger local identity, higher levels of happiness, and more self-reported knowledge about environmental issues. Study 1 draws on data from previously published cross-cultural studies (Schultz et al., 2005; Schultz \& Zelezny, 1999). Prior publications from this data set focused on values and the structure of environmental concern. However, the data set also contains a measure of local and global ratings of environmental problems, and thereby affords an opportunity to replicate and expand recent crosscultural findings by Gifford et al. (2009). Given the many complexities involved in obtaining cross-cultural data, secondary analyses of this existing data seemed warranted, at least as foundation for new data.

Because the original data does not have specific individuallevel measures of place identity, happiness, or knowledge, we draw from publicly available country-level data to gather variables tapping these constructs. Similarly, because no previous research has attempted to empirically explain spatial bias, we also include other individual-level (e.g., age, gender) and country- level variables (e.g., individualism, gross national product [GNP], Environmental Sustainability Index [ESI]) to explore the extent to which such variables can also predict spatial bias. However, given that our hypotheses are primarily at the level of the individual and not the country, such analyses should be interpreted with caution. In utilizing country-level data to test hypotheses about individual-level processes, we risk committing an eco- logical fallacy. Yet, with this precaution in mind, we believe that country- level predictors offer an interesting perspective on spatial bias, and we report them as exploratory. Especially relevant is the analysis using the ESI (an objective measure of environmental quality) as a predictor of spatial bias, which provides a test for the accuracy of 
individual beliefs about the relative quality of their local environmental conditions. In Study 2, we present new crosscultural data to extend this work by specifically testing our predictions with individual-level measures of place identity, happiness, and knowledge. 


\section{Study 1}

\section{Method}

Participants. Participants were university students recruited from psychology and social sciences courses in 22 countries: Argentina, Brazil, Canada, China, Columbia, Costa Rica, Czech Republic, Dominican Republic, El Salvador, Ecuador, Germany, India, Mexico, New Zealand, Panama, Paraguay, Peru, Romania, Russia, Spain, United States, and Venezuela. The data were collected over an 8-year period, from 1996 to 2004 (except data from China that were collected in 2010 and were not reported in the original publications). A target sample size of 90 was used in each country to provide adequate statistical power (.80) to detect a medium effect size $(r \sim$.30; Cohen, 1992); however, this was not achieved in all cases (see Table 1$)$. The students were mostly female $\left(n_{\text {females }}=2,072\right.$; $n_{\text {males }}=1,089 ; 116$ participants did not report gender) with an average age of $24(M=23.81, S D=6.99 ; 140$ participants did not report age). Most students $(n=787)$ reported growing up in a community with more than 1 million residents, although there was considerable variability $\left(n_{<10,000}=748 ; n_{10,001-100,000}=638\right.$; $\left.n_{100,001-500,000}=481 ; n_{500,001-1,000,000}=347\right)$. Similarly, most participants $(n=1,109)$ reported currently living in communities of 1 million or more residents $\left(n_{<10,000}=432\right.$; $\left.n_{10,001-100,000}=574 ; n_{100,001-500,000}=447 ; n_{500,001-1,000,000}=436\right)$.

\section{Materials}

\section{Individual-level measures}

Participants completed a paper-and-pencil questionnaire. Because the analyses are based on an existing data set, the measures were not included in the study specifically to test the current hypotheses. However, the study did include a measure of spatial bias in beliefs about environmental problems, along with several measures pertinent to our current hypotheses. The specific measures included in the present study are reported below, and descriptive statistics are presented in Table 2.

Environmental spatial bias. Spatial bias in environmental 
perceptions was measured using a set of items about the severity of six environmental problems: deforestation, water pollution, air pollution, land pollution, overpopulation, and global warming. Each item was rated once at the community level ("In your community, how serious is each of the following environmental problems?”) and once at the global level ("Worldwide, how serious is each of the following environmental problems?"). The items were measured on a 4point scale from 1 (extremely serious) to 4 (not at all serious). For evidence of structural invariance and discriminant validity of these two measures, see Schultz et al. (2005). 
Table 1. Demographic Characteristics of Each Sample, Means of Perceived Severity of Local and Global Environmental Problems, and ESI Scores.

Study $1(k=22, N=3,277)$

\begin{tabular}{|l|l|l|l|l|l|l|l|l|}
\hline Country & n & $\begin{array}{l}\text { Gender } \\
\% \\
\text { Female }\end{array}$ & $\begin{array}{l}\text { Mean } \\
\text { age }\end{array}$ & Local & Global & $\begin{array}{l}\text { Spatial } \\
\text { bias }\end{array}$ & $\begin{array}{l}\text { ESI } \\
2005\end{array}$ & $\begin{array}{l}\text { Scaled } \\
\text { ESI } \\
\text { (relative) }\end{array}$ \\
\hline Argentina & 54 & 59 & 22 & 2.39 & 1.81 & 0.59 & 62.7 & 0.51 \\
\hline Brazil & 208 & 73 & 27 & 2.47 & 1.56 & 0.91 & 62.2 & 0.49 \\
\hline Canada & 72 & 69 & 22 & 2.55 & 1.23 & 1.32 & 64.4 & 0.58 \\
\hline China & 71 & 17 & 21 & 2.04 & 1.48 & 0.56 & 38.6 & -0.46 \\
\hline Colombia & 130 & 78 & 23 & 2.23 & 1.64 & 0.60 & 58.9 & 0.36 \\
\hline Costa Rica & 199 & 61 & 25 & 2.75 & 1.38 & 1.38 & 59.6 & 0.38 \\
\hline $\begin{array}{l}\text { Czech } \\
\text { Republic }\end{array}$ & 113 & 66 & 24 & 2.11 & 1.33 & 0.78 & 46.6 & -0.14 \\
\hline $\begin{array}{l}\text { Dominican } \\
\text { Republic }\end{array}$ & 100 & 52 & 20 & 2.55 & 1.63 & 0.94 & 43.7 & -0.25 \\
\hline Ecuador & 167 & 49 & 28 & 2.14 & 1.56 & 0.57 & 52.4 & 0.10 \\
\hline $\begin{array}{l}\text { El } \\
\text { Salvador }\end{array}$ & 189 & 65 & 25 & 1.87 & 1.40 & 0.47 & 43.8 & -0.25 \\
\hline Germany & 120 & 75 & 26 & 2.17 & 1.32 & 0.85 & 57.0 & 0.28 \\
\hline India & 208 & 66 & 20 & 1.94 & 1.44 & 0.50 & 45.2 & -0.19 \\
\hline Mexico & 65 & 37 & 34 & 1.84 & 1.47 & 0.39 & 46.2 & -0.15 \\
\hline $\begin{array}{l}\text { New } \\
\text { Zealand }\end{array}$ & 217 & 65 & 25 & 2.47 & 1.37 & 1.10 & 61.0 & 0.44 \\
\hline Panama & 97 & 67 & 22 & 2.92 & 1.53 & 1.38 & 57.7 & 0.31 \\
\hline Paraguay & 200 & 61 & 23 & 2.55 & 1.59 & 0.96 & 59.7 & 0.39 \\
\hline Peru & 217 & 70 & 22 & 2.46 & 1.70 & 0.77 & 60.4 & 0.42 \\
\hline Romania & 296 & 84 & 27 & 3.27 & 3.60 & -0.33 & 46.2 & -0.15 \\
\hline Russia & 119 & 16 & 18 & 1.98 & 1.35 & 0.62 & 56.1 & 0.24 \\
\hline Spain & 103 & 64 & 21 & 2.19 & 1.67 & 0.51 & 48.8 & -0.05 \\
\hline $\begin{array}{l}\text { United } \\
\text { States }\end{array}$ & 169 & 70 & 21 & 2.50 & 1.46 & 1.04 & 53.0 & 0.12 \\
\hline Venezuela & 163 & 55 & 25 & 2.43 & 1.51 & 0.92 & 48.1 & -0.08 \\
\hline Study 2 $(k=8, N=1,131)$ & & & & & \\
\hline Argentina & 100 & 52 & 30 & 1.93 & 1.31 & 0.62 & 62.7 & 0.51 \\
\hline Brazil & 203 & 47 & 27 & 2.46 & 1.59 & 0.86 & 62.2 & 0.49 \\
\hline Colombia & 200 & 58 & 20 & 2.15 & 1.45 & 0.70 & 58.9 & 0.36 \\
\hline Japan & 237 & 41 & 20 & 3.04 & 1.66 & 1.39 & 57.3 & 0.29 \\
\hline
\end{tabular}




\begin{tabular}{|l|l|l|l|l|l|l|l|l|}
\hline Pakistan & 100 & 49 & 22 & 1.97 & 1.30 & 0.67 & 39.9 & -0.40 \\
\hline Portugal & 101 & 91 & 21 & 2.44 & 1.45 & 0.99 & 54.2 & 0.17 \\
\hline $\begin{array}{l}\text { New } \\
\text { Zealand }\end{array}$ & 96 & 62 & 21 & 2.46 & 1.49 & 0.97 & 61.0 & 0.44 \\
\hline Nigeria & 94 & 30 & 22 & 2.17 & 1.56 & 0.62 & 45.40 & -0.018 \\
\hline
\end{tabular}

Note: ESI = Environmental Sustainability Index. The following equation was used to calculate the scaled ESI scores: ESI / 25 - [50 / 25)]. In our calculations of scaled ESI, we used the grand mean of 50, which would correspond to the 50th percentile in the ESI rating system, rather than the grand mean from our sample of 30 countries. Both the measure of spatial bias and the scaled ESI range from -2 to +2 . Missing data were excluded on a casewise basis, so countrylevel demographics reported for Study 1 vary slightly from those reported in Schultz and Zelezny (1999), which used mean imputation. 
Table 2. Descriptive Statistics for the Scales Used in Studies 1 and 2.

\begin{tabular}{|c|c|c|c|c|c|}
\hline Scale & $\begin{array}{l}\text { Number } \\
\text { of items }\end{array}$ & $\begin{array}{c}\text { Cronbach's } \\
\alpha\end{array}$ & $\begin{array}{l}\text { Scale } \\
\text { range }\end{array}$ & $M$ & $S D$ \\
\hline \multicolumn{6}{|l|}{ Study 1} \\
\hline $\begin{array}{l}\text { Perceived severity of } \\
\text { global issues (higher } \\
\text { scores = better } \\
\text { environmental } \\
\text { conditions) }\end{array}$ & 06 & .89 & 1-4 & 1.69 & 0.81 \\
\hline $\begin{array}{l}\text { Perceived severity of } \\
\text { local issues (higher } \\
\text { scores = better } \\
\text { environmental } \\
\text { conditions) }\end{array}$ & 06 & .85 & $1-4$ & 2.41 & 0.80 \\
\hline $\begin{array}{l}\text { New environmental } \\
\text { paradigm }\end{array}$ & 15 & .71 & 1-5 & 4.62 & 1.40 \\
\hline $\begin{array}{l}\text { Egoistic environmental } \\
\text { concern }\end{array}$ & 04 & .85 & $1-7$ & 5.68 & 1.42 \\
\hline $\begin{array}{l}\text { Altruistic environmental } \\
\text { concern }\end{array}$ & 04 & .77 & 1-7 & 6.08 & 1.12 \\
\hline $\begin{array}{l}\text { Biospheric } \\
\text { environmental } \\
\text { concern }\end{array}$ & 04 & .87 & 1-7 & 5.91 & 1.19 \\
\hline $\begin{array}{l}\text { Inclusion of nature in } \\
\text { self }\end{array}$ & 01 & - & $1-7$ & 4.62 & 1.40 \\
\hline $\begin{array}{l}\text { Self-reported } \\
\text { proenvironmental } \\
\text { behavior }\end{array}$ & 12 & .81 & $1-5$ & 2.41 & 0.75 \\
\hline \multicolumn{6}{|l|}{ Study 2} \\
\hline $\begin{array}{l}\text { Perceived severity } \\
\text { of global issues }\end{array}$ & 06 & .83 & $1-4$ & 1.50 & 0.52 \\
\hline $\begin{array}{l}\text { Perceived severity of } \\
\text { local issues }\end{array}$ & 06 & .87 & 1-4 & 2.41 & 0.77 \\
\hline Happiness & 04 & .69 & $1-7$ & 5.04 & 1.05 \\
\hline Place identity & 08 & .86 & $1-5$ & 2.67 & 0.93 \\
\hline Perceived knowledge & 03 & .84 & $1-7$ & 3.96 & 1.33 \\
\hline
\end{tabular}

Note: Scores were calculated using the combined sample across studies.

Study 1: 22 countries $(N=3,277)$. Study 2: 8 countries $(N=1,131)$. 
The ratings were averaged to produce a measure of perceived local severity and global severity, and spatial bias was operationalized as the difference between local and global (average local minus average global; see Gifford et al., 2009). Lower scores reflect less spatial bias or less severity of environ- mental problems at the local level compared with the global level. In line with Gifford et al. (2009), higher scores represent more "optimism" (i.e., positive ratings) about the quality of the local environment relative to the global environment. To test for the validity of this indicator, an aggregated country-level correlation between our measure of spatial bias and the spatial bias scores reported in Gifford et al. was performed. Gifford et al. created their score from a different measurement tool which assessed 20 environmental conditions across 18 countries, 10 of which overlap with the set of countries included in our study, and we also added the New Zealand score obtained from Milfont et al. (2011, Study 1). A large significant effect was found, $r(n=11)=.84, p<$ .001 , supporting the validity of our spatial bias measure that was used as the dependent variable in all analyses.

New Ecological Paradigm (NEP) Scale. The NEP Scale measures the degree to which individuals view humans as part of nature rather than separate from nature and is used as an environmental attitudes measure (Dunlap, Van Liere, Mertig, \& Jones, 2000). The scale consists of 15 items that were averaged to create one composite score. The items were measured on a 4point scale from 1 (strongly agree) to 4 (strongly disagree) and later reverse scored so that higher values indicate greater proenvironmental attitudes. For review of cross-cultural studies using this scale, see Hawcroft and Milfont (2010).

Environmental Motives Scale (EMS). The EMS was used to measure concern about environmental issues (Schultz, 2001). This 12-item scale provides quantitative assessments of three types of environmental concerns: egoistic (me, my health, my lifestyle, my future), altruistic (all people, children, future generations, people in the community), and biospheric (plants, 
marine life, animals, birds; see Stern \& Dietz, 1994). Items were rated on a scale from 1 (not important) to 7 (supreme importance). Our analyses were performed using meancorrected scores. For evidence of structural invariance across countries and ethnic groups, see Schultz (2001) and Milfont, Duckitt, and Cameron (2006).

Inclusion of Nature in Self (INS) Scale. The INS is a singleitem scale measuring the degree of connectedness the individual feels with nature (Schultz, 2002). The higher the score, the more connected the individual feels with nature. Scores ranged from 1 (no connection) to 7 (complete connection).

Self-reported proenvironmental behaviors. A behavioral index was created from 12 self-reported conservation behavior items. Example of items include how often individuals recycled newspapers, cans, or bottles; encouraged others to recycle; purchased reusable or recyclable containers; picked up litter; and donated money to an environmental group. Items were rated on a scale from 1 (never) to 5 (very often). A mean score was created based on participant responses. For evidence of unidimensionality and structural invariance across cultures, see Schultz et al. (2005).

Demographic information. Additional questions were asked regarding age, gender, estimated size of the community in which the participant grew up, and estimated size of the community in which the participant currently resides.

\section{Country-level measures}

Although the explanations of spatial bias outlined above are based on individual-level theorizing, a set of five country-level variables were also included to examine their explanatory power of spatial bias. The indicators were publicly available to all countries included in the study. Three variables (happiness, media exposure, and ESI) were included to directly test

our predictions. Individualism and GNP scores were included for exploratory purposes because they have been shown to 
correlate to other psycho- logical constructs in cross-cultural studies (Leung \& Bond, 2004).

Happiness. Happiness was measured with the single item “All things considered, how satisfied are you with your life as a whole these days?” obtained from the World Database of Happiness (2007/2008). Individuals responded to this item using an 11-point scale ranging from 0 (dissatisfied) to 11 (satisfied). Media exposure. Media exposure was measured by creating an index of nine items obtained from the World Values Survey Database (2008). The items are as follows: (a) frequently watches TV (1 = do not watch, 2 = 1-2 hr per day, 3 = 2-3 hr per day, 4 = more than 3 hr per day), (b) how often do you use the PC ( 1 = never, 2 = occasionally, 3 = frequently, $4=$ don't know what a computer is), and information source $(0=$ not used last week, 1 = used last week), including (c) daily newspaper, (d) news broadcast on radio or TV, (e) printed magazine, (f) in-depth reports on radio or TV, (g) books, (h) Internet/email, and (i) talk with friends or colleagues.

ESI. This index scores countries based on their environmental performance in five domains: the maintenance of environmental systems at healthy levels, the extent of human impact on the environment, the level of environmental impact on humans, the social and institutional capacities to address environ- mental problems, and the level of global stewardship demonstrated by each country. The 2005 index was used as in Gifford at al. (2009) and obtained from Yale Center for Environmental Law and Policy (2005). The ESI score serves as an objective measure of environmental quality for each country.

Individualism. Individualism scores were obtained from Hofstede (2001).

Individualism represents the opposite of collectivism, and

describes the relationship between the individual and the collectivity that prevails in a given society. It is reflected in the way people live together-for example, in nuclear families, extended families, or tribes - and it has many 
implications for values and behaviors. (Hofstede, 2001, p. 209)

GNP. The GNP is an estimate of the country's economic welfare based on imports and exports. GNP was obtained from World Bank (2008).

Data Analyses. Given the nested structure of our data, analyses were con- ducted as a hierarchical linear model (Raudenbush \& Bryk, 2002). The hierarchical linear model utilizes data at the individual level and the country level, as well as possible crosslevel interactions. Country served as the Level 2 grouping variable, and analyses reported are based on grand mean centering. However, because our primary dependent variable (spatial bias) already had a meaningful zero point $(0=$ equal ratings for severity of local and global), this variable was analyzed in its raw form. Computations were per- formed in SPSS 18 using mixed linear and restricted maximumlikelihood (REML) estimation.

The model-building process proceeded in the following manner: The first step was to estimate an unconstrained model with no Level 1 (individual level) or Level 2 (country level) predictors. This null model was used to calculate the intraclass correlation coefficient (ICC; $\rho$ ), which measures the proportion of observed variation in spatial bias associated with country. In the second step, Level 1 variables were included to predict spatial bias. Level 2 variables were included as predictors of spatial bias in the final step. We used a multilevel model-building process in which we tested each Level 1 variable sequentially, beginning with the strongest predictor and removing nonsignificant predictors. The Level 2 predictors were then examined, again sequentially and removing nonsignificant predictors.

\section{Results}

Unconstrained Model. We began by examining spatial bias without using Level 1 (individual) or Level 2 (country) 
predictors. Results from this null model revealed a substantial degree of spatial bias, $\gamma_{00}=.77, t(21.24)=9.33, p<.001$. On average, ratings of environmental problems were rated as much worse at the global level, than the local level (average difference of .77). The random effects part of the model also showed a substantial amount of variability in spatial bias: between-participants variance $\left(\tau_{00}=.14\right)$ and withinparticipants variance $(\sigma=.56)$, yielding a $\rho=.20$. The ICC of .20 
indicates that $20 \%$ of the variation in spatial bias is attributable to country, whereas $80 \%$ of the variation is within-country, between-person variation. That is, respondents from the same country are more similar to each other/more different from respondents of other countries in terms of spatial bias. This effect (or ICC coefficient) is larger than those obtained in other large cross-cultural research, which has found around $10 \%$ to $12 \%$ of the variance between countries (see, for example, Owe et al., 2012). Due to such a large clustering effect, we can- not treat scores within country as independent for our further analyses (Luke, 2004). The equation for the random effects ANOVA is shown below in Equation 1.

$$
\text { (1) } Y_{i j}=\gamma_{00}+\mu_{0 j}+r_{i j} \text {. }
$$

Individual-Level Predictors. Next, we analyzed the data by sequentially entering Level 1 (individual level) predictors. The Level 1 predictors were age, gender, the size of community in which participant grew up, the size of the community in which participant currently resides, INS Scale, the three environmental concerns (altruistic, biospheric and egoistic), the NEP Scale, and self-reported proenvironmental behaviors. Six predictors were nonsignificant when entered singularly into the equation (INS Scale, the three environmental concerns, NEP, and proenvironmental behavior). The significant predictors in order of effect were as follows: gender, $\beta=.060, t(3,124.62)=$ $2.04, p<.05$; the size of the community in which the participant currently resides, $\beta=-.052, t(2,959.32)=-5.02, p$ $<.001$; the size of the community in which the participant grew up, $\beta=-.030, t(2,973.98)=-3.10, p<.01$; and age, $\beta=-.008$, $t(3,106.86)=-3.89, p<.001$.

The sequential analyses of the predictors revealed two uniquely and statistically significant predictors: the size of the community in which participant currently resides, $\beta_{1 j}=-.052$, $t(2,940.38)=-5.04, p<.001$, and age, $\beta_{2 j}=-.007, t(2,940.38)$ $=-3.49, p<.001$. The reported results are from the final 
equation with both significant predictors included in the model. Spatial bias was greater for younger individuals and for those currently living in smaller communities. The variability of this equation remains statistically significant $\left(\sigma_{\mathrm{ij}}=.53\right.$; $Z=38.21 ; p$ $<.001$ ), which indicates that other Level 1 variables are required to fully explain spatial bias. The equation for this Level 1 model is shown in Equation 2.

$Y_{i j}=\beta_{0 j}+\beta_{1 j} \quad($ current community size $)+\beta_{2 j} \quad$ (age $)+r_{i j}+$ $\mu 0_{j}$

Country-Level Predictors. In the next step, we analyzed five Level 2 predictor variables. Three predictors were nonsignificant when entered singularly into the equation (individualism, GNP, and media exposure). The significant 
Level 2 predictors of spatial bias were happiness, $\gamma_{01}=.251$, $t(17.30)=3.08, p<.01$, and ESI, $\gamma_{02}=.022, t(17.30)=2.31, p<$ .05 . These results are from the final equation with both predictors included in the model. Spatial bias was greater in countries with average higher scores in happiness and environmental sustainability. The estimate of betweenparticipant variance (or residual variance of the intercepts) was still significant, $\tau_{00}=.07, Z=2.74, p<.01$, indicating that happiness and ESI did not fully explain spatial bias and that other Level 2 predictors are required. The equations for this Level 2 model are shown in Equation 3.

Level 1: $Y_{i j}=\beta_{0 j}+r_{i j}$,

Level 2: $\beta_{0 \mathrm{j}}=\gamma_{00}+\gamma_{01}($ happiness $)+\gamma_{02}(\mathrm{ESI})+\mu_{0 \mathrm{j}}$.

Combined Model. In the final step, we combined the significant Level 1 and Level 2 predictors into a single model. All four variables (current com- munity size, age, country-level happiness, and country-level ESI) were still uniquely and statistically significant predictors of spatial bias. This final model decreased the between-participants variance $\left(\tau_{00}\right)$ from .14 to .06 and the within-participants variance $(\sigma)$ from .56 to .53 , demonstrating that the inclusion of these individual-level and country-level variables has explained a substantial amount of spatial bias. However, the estimates are still large and significant, indicating that there remains a significant amount of unexplained country-level variance and especially individuallevel variance on spatial bias.

\section{Discussion}

Study 1 reanalyzed published cross-cultural data to investigate spatial bias and its likely explanations. Supporting other crosscultural data (Dunlap et al, 1993; Gifford et al., 2009; Uzzell, 2000), results indicate strong environmental spatial bias across 22 countries, in which participants perceived environmental problems (deforestation, water pollution, air pollution, land pollution, overpopulation, and global warming) to be more 
severe worldwide than in their local community. This study also expands previous research by using a multilevel approach to investigate individual- and country-level predictors. Spatial bias was greater for younger individuals and for those with higher levels of concern about environmental issues, those respondents currently living in smaller communities, and respondents in countries with higher scores in happiness and environmental sustainability.

These results provide support for some of our predictions. First, there is indirect support suggesting that spatial bias may be linked to greater local identity. Residents of small towns (which are often also rural towns) have been shown to express stronger community ties (Ponzetti, 2003), so the question on current community size can be seen as a proxy indicator of identity to one's community. By living in smaller communities, participants experience greater local identity, which might lead them to discount serious environmental problems with the place they closely identify with. Higher levels of happiness reported in a country were also associated with greater spatial bias. This relationship was observed at the country level, whereas our predicted association between spatial bias and happiness was proposed at the individual level. We acknowledge the risk of committing the reverse ecological fallacy by assuming that relationships between variables at the individual level correspond to the same relationships at the culture level (Jargowsky, 2005). However, in line with evidence of a link between positive mood and increased self-serving bias (e.g., Tamir \& Robinson, 2007) and in support of our predictions, the findings suggest that the level of happiness experienced in a country can lead to self-serving assessments of environmental conditions, whereby these conditions are assessed as much better locally than elsewhere. Finally, media exposure in a country did not significantly predict spatial bias.

The reanalyses of published data in Study 1 allowed the replication of spatial bias in another large cross-cultural data set and the examination of some predictors of this bias, but has limited the test of specific predictions. To further explore this 
topic, Study 2 reports new cross-cultural data with new scales added to measure individual-level constructs hypothesized to be associated with spatial bias: happiness, place identity, and perceived knowledge about environmental issues.

\section{Study 2}

Method

Participants and Data Analyses. Participants for Study 2 were university students from eight countries $(N=1,131)$ :

Argentina, Brazil, Colombia, Japan, New Zealand, Nigeria, Pakistan, and Portugal. The data were collected over a 3-year period, from 2009 to 2011. The students were mostly female $\left(n_{\text {females }}=588 ; n_{\text {males }}=534 ; 9\right.$ participants did not report gender) with an average age of $22(M=22.71, S D=6.06 ; 28$ participants did not report age). Most students reported growing up in a community of 1 million or more residents $\left(n_{<10,000}=133 ; n_{10,001-100,000}=289 ; n_{100,001-500,000}=187 ; n_{500,001-}\right.$ $1,000,000=164 ; n_{>1,000,000}=311$ ), and also reported currently living in such large communities $\left(\mathrm{n}<10,000=77 ; \mathrm{n}_{10,001-100,000}=\right.$ $166 ; n_{100,001-500,000}=207 ; n_{500,001-1,000,000}=204 ; n_{>1,000,000}=$ 427).

Multilevel analyses were again performed using grand mean centered variables, except for spatial bias which was analyzed in its original units and for the three types of environmental concerns from the EMS, which were analyzed using meancorrected scores. For these analyses, we entered first as a block the demographic variables found to be significant predictors of spatial bias in Study 1 (age, gender, size of the community in whichparticipants grew up, and size of community participants currently live). We then entered the three new individual-level predictors (happiness, place attachment, and knowledge). Country-level predictors were not considered in this study because we have too few countries to yield reliable Level 2 parameters.

Besides the multilevel analyses, multigroup confirmatory factor analyses were also performed to test for the metric invariance of the three new measures across countries. Metric 
invariance is tested by constraining both the factor structure and factor loadings of each measure to be equal across groups. It is satisfied if the basic model structure and loading weights are invariant across groups, indicating that participants from different countries conceptualize the constructs and respond to the items in the same way (Milfont \& Fischer, 2010; Vandenberg \& Lance, 2000). The chi-square to degrees of freedom ratio $\left(\chi^{2} / d f\right)$, the comparative fit index (CFI), and the root mean square error of approximation (RMSEA; and its $90 \%$ confidence interval [CI]) were used to assess the degree to which the data fit the model. Models with $\chi^{2} / d f$, CFI, and RMSEA having values close to 3.0, 0.95, and .06, respectively, better indicate good fit (Carmines \& McIver, 1981; Hu \& Bentler, 1999). RMSEA values above .06 and .10 indicate mediocre and poor fit, respectively (Browne \& Cudeck, 1993). Multigroup confirmatory factor analyses were performed using LISREL 8.7 and maximum-likelihood estimation procedures, taking the observed covariance matrix as the input. Material. In this study, the same questionnaire as in Study 1 was used with the addition of three new measures.

Environmental spatial bias. As in Study 1, six items (deforestation, water pollution, air pollution, land pollution, overpopulation, and global warming) were rated once at the community level and once at the global level. Cronbach's alphas ranged from .78 (Pakistan) to .86 (Brazil; $\alpha_{\text {average }}=.83$ ) for the local-level scale, and from .70 (Portugal) to .91 (Brazil; $\alpha_{\text {average }}=.79$ ) for the global- level scale. Metric invariance testing was then performed for each scale.

Fit indices for the local scale were satisfactory and full metric invariance was deemed acceptable: $\chi^{2}(107)=245.04 ; \chi^{2}$ $/ d f=2.29 ; \mathrm{CFI}=.96$; and RMSEA $=.096 ; 90 \% \mathrm{CI}=[.080$, .11]. Fit indices for the global scale were poorer: $\chi^{2}(107)=$ 327.47; $\chi^{2} / d f=3.06$; CFI = .93; and RMSEA = .12; $90 \%$ $\mathrm{CI}=[.11, .14]$. Modification indices suggested that the first global item (deforestation) was noninvariant across countries. Allowing this item loading to vary across groups improved fit slightly: $\chi^{2}(100)=277.99 ; \chi^{2} / d f=2.78$; CFI $=.94$; and RMSEA $=.11 ; 90 \% \mathrm{CI}=[.097, .13]$. Partial metric invariance 
for the global scale was deemed acceptable. Once again, spatial bias was operationalized as the difference between the two scores (local minus global). 
This spatial bias score was used as the dependent variable in all further analyses.

Happiness. The subjective happiness scale measures current state of happiness (Lyubomirsky \& Lepper, 1999). The measure contains four items: "In general, I consider myself ... . " (on a 7-point scale anchored by not a very happy person and a very happy person); "Compared to most of my peers, I consider myself ... " (on a 7-point scale anchored by less happy and more happy); "Some people are generally very happy. They enjoy life regardless of what is going on, getting the most out of everything. To what extent does this characterization describe you?"; and "Some people are generally not very happy. Although they are not depressed, they never seem as happy as they might be. To what extent does this characterization describe you?” (both on a 7-point scale anchored by not at all and a great deal). Cronbach's 
alphas ranged from .44 (Pakistan) to .86 New Zealand $\left(\alpha_{\text {average }}=\right.$ .66). This measure showed acceptable metric invariance across countries: $\chi^{2}(37)=102.08 ; \chi^{2} / d f=2.76$; CFI $=.95$; and RMSEA $=.11 ; 90 \% \mathrm{CI}=[.086, .14]$. Modification indices suggested that the last item was noninvariant across countries, and allowing this item loading to vary across groups improved fit substantially: $\chi^{2}(30)=53.09 ; \chi^{2} / d f=1.77$; CFI $=.98$; and RMSEA $=.074 ; 90 \% \mathrm{CI}=[.040, .11]$. Partial metric invariance was thus supported.

Place Identity Scale. This scale measures the extent to which individuals believe that their current residency location is part of their identity. Following on Breakwell's (1993) four processes model of identity, place-related continuity, self-esteem, selfefficacy, and distinctiveness were measured using eight items (e.g., "I feel a sense of togetherness with others who live here"). This scale is rated from 1 (strongly agree) to 5 (strongly disagree). The scale was reverse scored so that higher numbers represent greater place identity. Cronbach's alphas ranged from .81 (Portugal) to .94 (Argentina; $\alpha_{\text {average }}=.86$ ). Some evidence of metric invariance across countries was observed: $\chi^{2}(209)=$ 785.57; $\chi^{2} / d f=3.76$; CFI = .91; and RMSEA $=.14 ; 90 \% \mathrm{CI}=$ $[.13, .15]$. Freeing loadings of three items with higher modification indices to vary across groups did not substantially improve fit: $\chi^{2}$ $(188)=723.00 ; \chi^{2} / d f=3.76 ; \mathrm{CFI}=.92 ;$ and RMSEA $=.14 ; 90 \%$ $\mathrm{CI}=[.13, .15]$. 
Knowledge. Three questions measured the degree of knowledge the individual has for the country they live, their current community, and worldwide environmental problems. Participants indicated how knowledgeable they are about environmental problems in these three spatial locations on a scale ranging from 1 (not knowledgeable) to 7 (very knowledgeable). Cronbach's alphas ranged from .59 (Pakistan) to .94 (Argentina; $\alpha_{\text {average }}=.80$ ). Considering this scale has only three items, no item was specified to load with a known value when testing the invariance models to aid model identification. This measure showed some evidence of metric invariance across countries: $\chi^{2}$ $(21)=103.58 ; \chi^{2} / d f=4.93 ;$ CFI $=.93$; and RMSEA $=.17 ; 90 \%$ $\mathrm{CI}=[.14, .20]$.

Before moving to the main results, it is important to mention that the information reported above indicates some low reliabilities and weak metric invariance for certain countries and scales. These poor psychometric parameters may attenuate correlations and confidence in the results reported in the following. However, Leung and Bond (2004) have argued that psychological constructs should be viewed as universal for practical purposes provided that they show a good level of similarity across cultures. Marsh (1994) also noted that when "the lack of invariance is sufficiently small," one can conclude that the "parameter estimates are reasonably invariant across groups” (p. 16). Taken these considerations into account, we deem the psychometric properties and invariance of the scales tenable for the current purposes. If results from this study replicate those from Study 1, it will provide further support for the crosscultural validity of the scales.

\section{Results}

Unconstrained Model. The unconstrained model without Level 1 (individual) predictors was tested first (see Equation 1). Results from the null model again revealed a substantial degree of spatial bias, $\gamma_{00}=.85, t(7.17)=9.11, p<.001$. On average, ratings of environmental problems in these eight countries were worse at the global level than the local level (average difference of .85). The between-participants variance (country level, $\tau_{00}=.07$ ) and the within-participants variance (individual level, $\sigma=.49$ ) 
yielded an ICC $(\rho)$ of .13. This indicates that $13 \%$ of the variation in spatial bias is attributable to country. This ICC coefficient is smaller than the one for Study 1 (i.e., 20\%) but similar to those obtained in other cross-cultural research (see Owe et al., 2012).

Individual-Level Predictors. We then entered the four demographic predictors in the model as a block. The significant predictors in order of effect were the size of the community in which participant grew up, $\beta=-.039, t(1,040.40)=-1.93, p=$ .054 , and age, $\beta=-.013, t(978.17)=-2.98, p<.01$. Replicating Study 1 , spatial bias was greater for younger individuals. Spatial bias was also greater for those who grew up in smaller communities, whereas for Study 1, it was greater for those currently living in smaller communities.

We kept the demographic predictors in the model and then independently entered each of the three individual-level predictors (happiness, place attachment, and knowledge). The only significant predictor of spatial bias was happiness, $\beta=.044$, $t(1,000.54)=2.06, p<.05$, and hometown community size and age were still uniquely and statistically significant predictors, $\beta$ $=-.039, t(1,001.19)=-1.90, p=.058$, and $\beta=-.012, t(935.29)$ $=-2.65, p<.01$, respectively. These results are from the final equation with all four demo- graphic predictors and happiness included in the model. Spatial bias was greater for those individuals who reported higher levels of happiness. The variability of this equation remains statistically significant $\left(\sigma_{i j}=\right.$ $.49 ; Z=22.32 ; p<.001$ ), which indicates that other Level 1 variables are required to fully explain spatial bias. The equation for this Level 1 model is shown in Equation 4 below. 


$$
\begin{gathered}
Y_{i j}=\beta_{0 j}+\beta_{1 j} \text { (happiness) }+\beta_{2 j} \text { (hometown community } \\
\text { size })+\beta_{3 j} \text { (age) }+r_{i j}+\mu_{0 j} .
\end{gathered}
$$

Spatial Bias or Accurate Perceptions? Throughout this article, we have operationalized spatial bias as local minus global ratings of environmental quality. However, the results from Study 1 and from Gifford et al. (2009) show that spatial bias is predicted by the ESI score of the country. This finding suggests that what we have termed bias may in fact reflect accurate ratings. Indeed, some countries do have a better local environmental quality compared with the global average, although certainly not all of them. Gifford et al.'s accuracy explanation and our (unsupported) hypothesis that spatial bias would be greater for participants with more knowledge about environmental issues follow this idea. To further explore this issue, we pooled the data from our two studies and conducted a supplemental analysis of ESI and spatial bias using scores from our 26 countries and 30 samples. These data are shown in Table 1. Across the 30 samples, environmental problems were seen as worse on a global level $(M=1.56, S D=.41$; scale from $1=$ extremely serious to $4=$ not at all serious) than a local level $(M=$ $2.35, S D=.35$ ). The average spatial bias effect was .79 (local minus global; $S D=.35)$. As expected, spatial bias was positively and significantly correlated with ESI, $\beta=.47, t(28)=2.83, p<.01$; constant $=-.38$; unstandardized coefficient $(b)=.022$. The scatter plot showing this relationship is presented in Figure 1, along with the regression line for the subjective bias scores (shown as dotted). We then proceeded to create an "objective" score by scaling the original ESI units (from 1 to 100) to the same units as the environmental ratings for local and global (from 1 to 4 ), and then converting these to reflect the relative difference between the local (using the scaled score) minus the global (scaled using the absolute grand mean of 50). The resulting objective index 


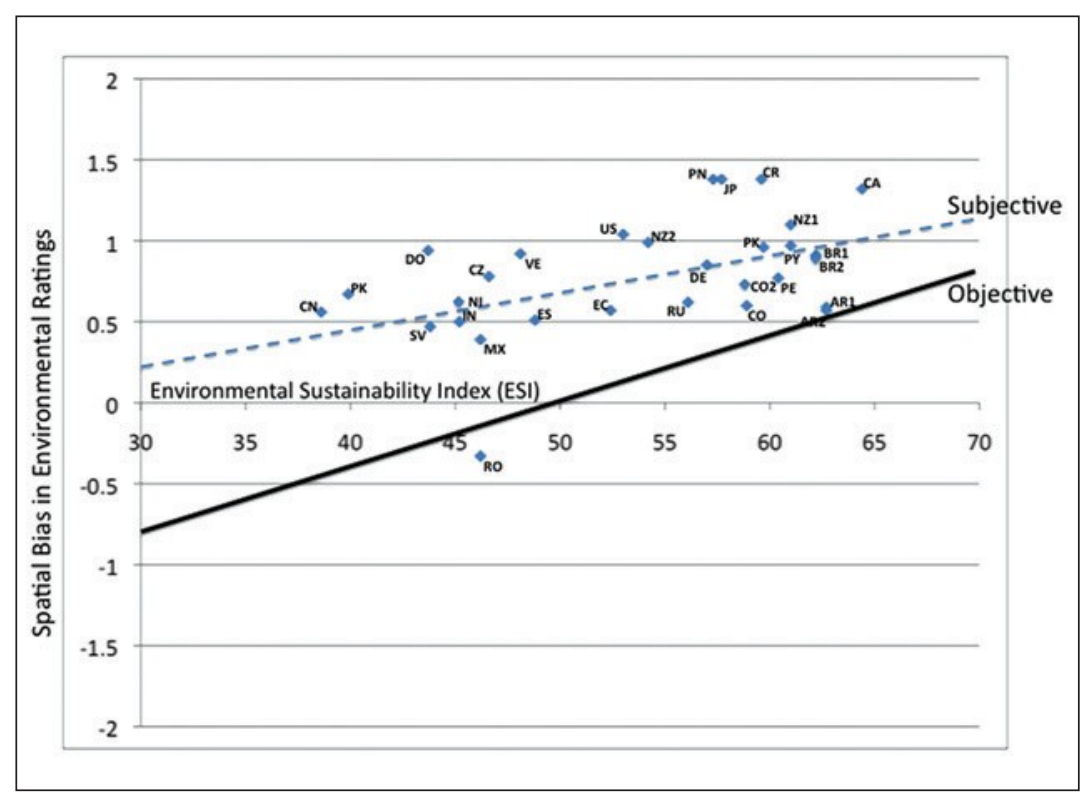

Figure 1. Spatial bias in beliefs about the severity of environmental problems across 26 countries and 30 samples.

Note: ESI = Environmental Sustainability Index. Dots represent each of the 30 samples reported in the two studies. The dashed line represents the bivariate regression equation using ESI to predict subjective bias scores (calculated as severity ratings at the local level minus severity ratings at the global level; range from -2 to +2 ). The solid line represents the scaled objective quality of the local environment, relative to the global environment calculated using the ESI score (range from -2 to +2 ). Country labels: AR1 = Argentina $($ Study 1); AR2 = Argentina (Study 2); BR1 = Brazil (Study 1); BR2 = Brazil (Study 2); CA = Canada; CN = China; CO1 = Colombia (Study 1); CO2 = Colombia (Study 2); CR = Costa Rica; CZ = Czech Republic; $\mathrm{DO}=$ Dominican Republic; EC = Ecuador; SV = El Salvador; DE = Germany; IN = India; MX = Mexico; NZ1 = New Zealand (Study 1); NZ2 = New Zealand (Study 2); $\mathrm{NI}=$ Nigeria; $\mathrm{PA}=$ Panama; $\mathrm{PK}=$ Pakistan; $\mathrm{PY}=$ Paraguay; $\mathrm{PE}=$ Peru; $\mathrm{RO}=$ Romania; RU = Russia; ES = Spain; US = United States; VE = Venezuela.

is shown in Table 1 . Scores range from -2 to +2 , indicating the degree to which the country is above or below the worldwide average. Scores of 0 indicate a country that is at the 50th percentile (i.e., the average); positive scores indicate countries with better-than-average environmental records, and negative scores indicate countries with worse-than-over environmental 
records. These scores should be interpreted with caution, as they are based on a number of underlying assumptions, but we present them here as a starting point for assessing the validity of the "bias" measures. These scale scores provide an "objective" assessment of the relative quality of the local environment compared with the global. Because the scaled ESI score is in the same units as our measure of spatial bias, the objective scores can then be plotted in the same scatter plot. For comparison, we plotted the objective spatial bias score using ESI on the same graph, constant $=-2.00$; unstandardized coefficient $(b)=.04$. For clarity of presentation, we have plotted the ESI range of our countries (from 30 to 70) rather than the full 1 to 100 range of possible ESI scores. For each country, the degree to which the spatial bias score deviates from the plotted objective line represents "bias." Note that in every case (except for Romania), the subjective bias scores are above the objective line (i.e., they are indeed biased). Despite the outlier of Romania, the slopes of the two lines (subjective = .022 , objective $=.04$ ) are quite similar, suggesting a generally consistent amount of bias across the differing levels of country environmental quality.

\section{Discussion}

This eight-country cross-cultural data provide further evidence of spatial bias. Participants perceived worldwide environmental problems to be more severe than those in their local community. The findings support those from Study 1 as well as other cross-cultural data (Dunlap et al., 1993; Gifford et al., 2009; Uzzell, 2000). The inclusion of specific measures aided the test of possible explanations of spatial bias. Supporting predictions, and overall replicating findings from Study 1, spatial bias was greater for those individuals who reported higher levels of happiness, who were younger, and for those who grew up in smaller communities. Additional analyses also showed that although spatial bias is correlated with objective environmental conditions, they are still indeed "biased." 


\section{General Discussion}

This article reports results from two cross-cultural studies examining spatial bias and its possible explanations. Several previous studies have shown that individuals perceive the severity of environmental problems as greater at the global level compared with the local area they live. Strong spatial bias was observed across participants from 22 countries (Study 1) and 8 countries (Study 2). We describe three possible explanations for this perceptual bias. We predicted that spatial bias would be greater for participants with stronger place identity, with higher levels of happiness, and higher knowledge about environmental issues. We only found evidence for the association between spatial bias and happiness. In the following sections, we provide a more detailed discussion of each of the significant contributions of this research.

Spatial Bias as a Universal Psychological Phenomenon One of the clearest findings from this study was the large degree of spatial bias in environmental perceptions found across our large cross-cultural data. The pervasive nature of this effect might suggest that it is a universal psychological phenomenon. Human psychological universals have been conceptualized as "core mental attributes that are shared at some conceptual level by all or nearly all non-brain-damaged adult human beings across cultures" (Norenzayan \& Heine, 2005, p. 763). There is now strong cumulative evidence that spatial bias is experienced by individuals across many cultures. Indeed, our study is consistent with a large cross-cultural body of data showing spatial bias from individuals from at least 40 countries (Dunlap et al., 1993; Gifford et al., 2009; Uzzell, 2000). Moreover, the independent scores of spatial bias are significantly correlated across the three larger cross- cultural studies. The Dunlap et al.'s (1993) score is significantly associated with the Gifford et al.'s (2009) scores ( $\rho=.85, p<$ $.001)$ and our scores $(\rho=.42, p<.01)$, which are also significantly associated with each other $(\rho=.64, p<.001){ }^{1}$ These results provide substantial cross-cultural evidence of 
spa- tial bias and the possibility that this psychological phenomenon is universal. In their analysis of psychological universals, Norenzayan and Heine (2005) discussed a hierarchical taxonomy to describe four degrees of universality that can be observed cross-culturally. The taxonomy is derived from three questions about the comparability of a particular psychological trait or phenomenon across cultures: (a) Is the particular psychological phenomenon the same or different across cultures? (b) Even if the phenomenon is the same or nearly the same, do people from different cultures express the phenomenon in the same situations? and (c) Even if the phenomenon is the same, and is expressed in the same situations, is the phenomenon expressed with the same facility or frequency across cultures? The answers to these questions yield one case of non- universal and three levels of universals: nonuniversals (psychological phenomenon different across cultures; for example, certain statistical and dialectical reasoning strategies that are historically and culturally bound), existential universals (same phenomenon but expressed in different ways; for example, rules in similarity judgments), functional universals (same phenomenon and same functional expression but differential accessibilities; for example, internal attributions of causality), and accessibility universals (same phenomenon, expression, and degree of accessibility; for example, the mere exposure effect). This taxonomy serves as a useful heuristic to assess the universality of spatial bias. Considering that spatial bias has been observed in a large number of countries and via different measurement strategies, it seems reasonable to propose that spatial bias is a plausible functional universal candidate. Spatial bias seems to be cognitively available to people in many cultures and has functionally the same expression across cultures (i.e., serves as an awareness buffer of the severity of environmental problems in one's local area), but also seems to vary in its accessibility (see discussion below). Future studies in the area should focus on testing this possibility further. 
One goal of this article was to provide independent evidence of spatial bias across cultures, as discussed above. A second goal was to provide some possible explanations of this phenomenon. We proposed and tested three explanations. First, we predicted that environmental spatial bias would be greater for individuals with stronger place identity. This prediction was based on an identity perspective whereby individuals would tend to discount the severity of local environmental problems to maintain a positive local identity (see Hugh- Jones \& Madill, 2009). Second, we predicted that environmental spatial bias would be greater for individuals reporting higher levels of happiness, which was based on evidence of a boosting effect of positive mood on self-serving biases (Tamir \& Robinson, 2007). Finally, Gifford et al. (2009) have suggested an accuracy explanation for spatial bias, arguing that media exposure might have increased awareness and concern for global environmental problems (more so than for local environmental problems). We thus predicted that spatial bias would be greater for individuals reporting more knowledge about environ- mental issues. In other words, we aimed to test whether spatial bias was more accessible, as a psychological phenomenon, to those expressing more positive place identity, to those with greater dispositional happiness, and to those with more perceived knowledge about environmental problems.

We found some evidence for the place identity explanation. In both studies, spatial bias was greater for individuals who are currently living (Study 1) or grew up (Study 2) in smaller communities. Residents of small towns tend to express stronger community ties (see Ponzetti, 2003), and research has also shown that environmental attitudes are stronger for children from rural areas than for urban children (Bunting \& Cousins, 1985). Based on these previous findings, it seems plausible that individuals who grow up and are living in smaller communities might have a more positive local identity, which might explain their tendency to discount serious environmental problems in the place they closely identify with. In this context, spatial bias seems to express a "place- serving bias" through which individuals 
protect their local community from any association with damaging environmental problems. Although community size can be seen as a proxy indicator of identity to one's community, a specific mea- sure of place identity did not significantly predict spatial bias in Study 2. Therefore, the "place-serving bias" account seems reasonable, but its influence on spatial bias perhaps is better captured indirectly via community size rather than a direct measure of place identity. Future studies could try to tease this out. We found stronger evidence for the happiness explanation. Spatial bias was greater in countries with average higher scores in happiness (Study 1) and also for individuals with greater dispositional happiness (Study 2). An explanation for this association between happiness and spatial bias can be found in research demonstrating the influence of positive mood on increased cognitive flexibility and self-serving biases (e.g., Hirt et al. 2008; Murray et al., 1990; Tamir \& Robinson, 2007). Happy individuals are more likely to find positivity in their environment and are more flexible when processing information required for self-serving perceptions. In this regard, positive mood might increase the psychological principle of confirmation or assimilation bias, wherein people tend to favor information, as well as to interpret disconfirming evidence in a biased manner, that supports their preconceptions (Lord, Ross, \& Lepper, 1979). By serving as a negativity buffer and selfenhancer, happiness can thus lead to self-serving assessments of environmental conditions, whereby these conditions are assessed as much better locally than elsewhere.

Spatial bias was also associated with age in both studies, with greater spatial bias for younger individuals. This association was not predicted but can per- haps be explained in terms of the associations between age and environmental engagement in general. Research has shown that younger individuals tend to be more environmentally concerned than older individuals (Fransson \& Gärling, 1999; Hawcroft \& Milfont, 2010; Hines, Hungerford, \& Tomera, 1986/1987; Van Liere \& Dunlap, 1980). It could be speculated that spatial bias tends to be greater for more environmentally engaged individuals, which often 
includes younger individuals. This is in line with the countrylevel findings showing that spatial bias is greater in countries with average higher scores in environ- mental sustainability. Future studies should examine this possibility further.

Taken in conjunction, the influence of happiness, community size, and age on spatial bias support the argument put forward previously that although pervasive, this psychological phenomenon varies in its accessibility. We provide evidence that spatial bias seems to be more accessible to those who are younger, happier, and from smaller communities. There is also evidence suggesting that spatial bias is greater in developed than in developing countries. In their cross- cultural study, Dunlap et al. (1993) gathered data from 12 industrialized and 12 developing countries, and in one question asked participants ( $N$ $=29,708$ ) to rate the quality of the environment for their nation, their local community, and the world as a whole. A visual inspection of their Figure 4 clearly shows that participants in industrialized countries were more likely to rate the quality of the world's environment as "very" or "fairly" bad compared with participants in the developing countries. Additional analyses of their data show that the average spatial bias score was much higher for industrialized countries (58.75) than developing countries (17), and that spatial bias was absent or very small in 5 of the developing countries (India, Poland, Russia, South Korea, and Turkey). ${ }^{2}$ Their explanation for this difference between industrialized and developing countries in the assessment of local and global environments is similar to the argument of the environmental deprivation theory (Tremblay \& Dunlap, 1978). Dunlap et al. (1993) argued that the local environment is viewed less positively than the global environment in developing countries due to their "first-hand observation of or experience with environmental deterioration" (p.13). In other words, spatial bias is less accessible in individuals from developing countries due to their greater exposure to pollution and environmental degradation.

Because these findings suggest varying accessibility of spatial bias in relation to differences in happiness, community 
size, age, and experience with environmental problems, this psychological phenomenon cannot be seen as an accessibility universal (Norenzayan \& Heine, 2005). However, our findings show that spatial bias is pervasive and does not reflect accurate ratings of environmental problems (i.e., it is indeed biased; Figure 1). Further support for spatial bias comes from the Milfont et al.’s (2011, Study 2) article. Because spatial bias has been linked to comparative optimism, they examined whether individual differences in optimism could explain this bias. They found that dispositional optimism did not attenuate spatial bias. Therefore, there exists strong evidence to support spatial bias as a candidate of functional universal.

\section{Caveats and Limitations}

Although the reported research provides a large and diverse cross-cultural data set, there are a number of limitations that should be noted. First, we proposed and tested three possible explanations of spatial bias, but this was not an exhaustive list. For instance, in broad social-psychological terms, spatial biases could be explained as a general process analogous to stereotyping. Similar to the assessments toward individuals from an "out-group," environmental assessments of distant locations would be more negative and more similar than the environmental assessments of one's own location. Distance assessment studies have provided some evidence in this direction (Palma-Oliveira, Nunes, \& Van der Kellen, 2009). Second, although we claim that spatial bias is a dis- tinct psychological phenomenon, it is still to be empirically tested whether this bias is merely a special case of optimism bias or indeed unique. Some scholars have framed spatial bias in terms of comparative optimism (Gifford et al., 2009; Hatfield \& Job, 2001; Pahl et al., 2005), but perhaps comparative optimism and spatial bias are special cases of a broader cognitive process.

For example, Milfont (2010; Milfont et al., 2011) have recently used construal level theory (Liberman \& Trope, 2008; Trope \& Liberman, 2003) as a framework for explaining spatial and temporal biases related to the perception of environmental 
problems. According to this theory, an event is more psychologically distant when it takes place farther into the future (temporal distance), when it occurs in more remote locations (spatial distance), when it is less likely to occur (hypothetical distance), and when it happens to people dissimilar from oneself (social distance). Events that are psychologically distant are viewed in more abstract and superordinate terms (high-level construals), whereas events psychologically closer are viewed in more concrete and detailed terms (low- level construals). High-level mental representations are more abstract, simpler, coherent, and more schematic than low-level representations.

Environmental conditions are often uncertain (hypothetical distance), take place farther into the future (temporal distance), and are perceived to be more likely to occur in distant geographical locations (spatial distance) and to people less like oneself (social distance). Milfont (2010) argued that because environmental conditions are psychologically distant, they are assessed with a high level of construal. Given that environmental conditions are already similarly assessed in terms of more schematic and abstract level of mental representation, any specific assessment that highlights distance would increase this high-level representation and would lead to similar biases.

In line with construal level theory, Milfont (2010) contended that the biases in the assessment of environmental conditions can be explained by the underlying high-level mental representation they share. That is, the psycho- logical mechanism associated with representing an object or situation (in this case, environmental conditions) in a high-level construal lead to similar assessments of the object or situation. For example, the assessment of environmental conditions that take place farther into the future, and are perceived to be more likely to occur in distant geographical locations and to people less like oneself, will be represented at a high level of construal and, as a result, will be similarly assessed. Empirical findings seem to support this view, with 
similar biases in the assessment of environmental conditions shown for temporal distance (Gifford et al., 2009), spatial distance (Uzzell, 2000), and social distance (Fleury-Bahi, 2008). Thus, it is maintained that these biases are a reflection of the underlying high-level mental representation of environmental conditions. Similarly, some cognitive biases, such as comparative optimism and spatial bias, are to some extent analogous because they all involve some type of psychological distance (e.g., social and spatial dis- tance), and as a result have underlying high-level mental representations of the distant object. Using construal level theory for integrating cognitive biases seems a fertile area for future theoretical and empirical research.

Finally, there are a number of methodological limitations that temper our conclusions. First, our cross-cultural samples were from university students. Such samples are likely to be more educated and more affluent than the populations of the countries from which they were drawn. We attempted to generate comparable data sets across countries by sampling lowerdivision psychology or social science courses, but the data cannot be considered representative of the general population. This limitation is partially allayed through our comparison of spatial bias across three independent cross-cultural data sets, where our country-level bias scores correlated with Gifford et al.'s (2009) nonstudent samples ( $\rho=.64)$ and Dunlap et al.'s (1993) probability samples ( $\rho=.42$; see Table 3 ). Another limitation in our data is the timespan across which data were collected. The data from Study 1 were collected during 19962004, whereas the data for Study 2 were collected during 20092011. Although environmental issues are often slow to develop (and ESI thereby remains relatively stable over time), our combined analyses did not consider time or year of sample as a variable. 


\section{Conclusion}

Spatial bias is the tendency to perceive environmental problems as more severe at the global level than at the local level. The present article reports data from two cross-cultural data sets that support previous findings showing the crosscultural prevalence of spatial bias, and going beyond previous studies, the article also tests possible explanations for this bias. Findings indicate that happiness, community size (which might be indirectly linked to place identity), and age are associated with spatial bias so that this bias is more accessible for those who are happier, younger, and have grown up or are currently living in smaller communities. By serving as an awareness buffer for the severity of environmental problems in one's local area, spatial bias expresses self-serving as well as a "placeserving” biases. We argue that the cumulative cross-cultural evidence for spatial bias makes it a plausible functional universal candidate because it is the same phenomenon and is expressed similarly in same situations across cultures, but is expressed with varying facility or frequency across particular groups. 
Table 3. Summary of Spatial Bias From Large Cross-Cultural Data Sets.

\begin{tabular}{|c|c|c|c|}
\hline & $\begin{array}{l}\text { Dunlap, Gallup, } \\
\text { and Gallup (1993) }\end{array}$ & $\begin{array}{l}\text { Gifford et al. } \\
\text { (2009) }\end{array}$ & $\begin{array}{l}\text { Schultz et al. } \\
\text { (current study) }\end{array}$ \\
\hline Country & $\begin{array}{c}\text { (range }= \\
-99 \text { to }+99)\end{array}$ & $\begin{array}{l}\text { (range }= \\
-3 \text { to }+3 \text { ) }\end{array}$ & $\begin{array}{l}\text { (range }= \\
-2 \text { to }+2 \text { ) }\end{array}$ \\
\hline Argentina & & & 0.61 \\
\hline Australia & & 1.16 & \\
\hline Brazil & 23 & 0.60 & 0.89 \\
\hline Canada & 61 & 1.35 & 1.32 \\
\hline Chile & 47 & & \\
\hline China & & & 0.56 \\
\hline Colombia & & & 0.65 \\
\hline Costa Rica & & & 1.38 \\
\hline Czech Republic & & & 0.78 \\
\hline Denmark & 80 & & \\
\hline Dominican Republic & & & 0.94 \\
\hline Ecuador & & & 0.57 \\
\hline El Salvador & & & 0.47 \\
\hline England & & 0.94 & \\
\hline Finland & 60 & 1.16 & \\
\hline France & & 0.92 & \\
\hline Germany & 64 & 0.79 & 0.85 \\
\hline Hungary & 23 & & \\
\hline India & -02 & 0.03 & 0.50 \\
\hline Italy & & 0.59 & \\
\hline Ireland & 63 & & \\
\hline Japan & 42 & 0.47 & 1.38 \\
\hline Mexico & 39 & 0.25 & 0.39 \\
\hline Netherlands & 60 & 0.76 & \\
\hline New Zealand & & 1.21 & 1.04 \\
\hline Nigeria & -10 & & 0.62 \\
\hline Norway & 78 & & \\
\hline Pakistan & & & 0.67 \\
\hline Panama & & & 1.38 \\
\hline Paraguay & & & 0.96 \\
\hline Peru & & & 0.77 \\
\hline Philippines & 30 & & \\
\hline Poland & 02 & & \\
\hline Portugal & -45 & 0.32 & 0.99 \\
\hline Romania & & -0.30 & -0.33 \\
\hline
\end{tabular}




\begin{tabular}{|c|c|c|c|}
\hline & $\begin{array}{c}\text { Dunlap, Gallup, } \\
\text { and Gallup (1993) }\end{array}$ & $\begin{array}{c}\text { Gifford et al. } \\
\text { (2009) }\end{array}$ & $\begin{array}{c}\text { Schultz et al. } \\
\text { (current study) }\end{array}$ \\
\hline Country & $\begin{array}{c}\text { (range }= \\
-99 \text { to +99) }\end{array}$ & $\begin{array}{c}\text { (range }= \\
-3 \text { to +3) }\end{array}$ & $\begin{array}{c}\text { (range }= \\
-2 \text { to +2) }\end{array}$ \\
\hline Russia & $\mathbf{- 0 3}$ & $\mathbf{- 0 . 1 2}$ & 0.62 \\
\hline South Korea & 08 & & \\
\hline Spain & & 0.64 & 0.51 \\
\hline Sweden & & 1.20 & \\
\hline Switzerland & 65 & & \\
\hline Turkey & 01 & & \\
\hline United Kingdom & 49 & & \\
\hline Uruguay & 46 & & 0.92 \\
\hline United States & 38 & 0.65 & \\
\hline Venezuela & & & \\
\hline
\end{tabular}

Note: Bold-faced scores indicate instances of nonspatial bias. Data from England and United Kingdom were treated as from distinct countries. Calculation of scores from the Dunlap et al. (1993, Figure 4) data set is described in Footnote 3 of their study. Scores were calculated from the Gifford et al. (2009, Table 3) data set by subtracting the mean ratings of current global environmental conditions from the mean ratings of current local environmental conditions; data from New Zealand were obtained from Milfont et al. (2011, Study 1). The scores for Argentina, Brazil, Colombia, and New Zealand in the Schultz et al. column are the averages from Studies 1 and 2. The virtually identical scores obtained for these four countries in independent studies several years apart provide support for the stability of spatial bias (see our Table 1). 


\section{Authors' Note}

P. Wesley Schultz and Taciano L. Milfont contributed equally to the writing of this article. The data were collected with assistance from many colleagues, including Linda D. Cameron, Geetika Tankha, Peter Schmuck, Marek Franek, and Wang Xia.

\section{Acknowledgments}

We acknowledge Teressa Cho and Samantha PobogJaworowski for their help with data collection in New Zealand for Study 2.

\section{Declaration of Conflicting Interests}

The author(s) declared no potential conflicts of interest with respect to the research, authorship, and/or publication of this article.

\section{Funding}

The author(s) disclosed receipt of the following financial support for the research, authorship, and/or publication of this article: Study 1 reports a reanalysis of cross- cultural data collected with grant support from the Society for the Psychological Study of Social Issues (SPSSI). The writing of this article was supported in part by a sabbatical grant awarded to Taciano L. Milfont by the Victoria University of Wellington.

\section{Notes}

1. Spearman's rho correlations were computed between the scores because of the ordinal nature of the data. Considering that not all countries overlapped, the SPSS Multiple Imputation command was used to fill empty cells and yield data for all 45 countries (for a similar approach, see Smith, Peterson, \& Schwartz, 2002).

2. Spatial bias scores were calculated from the Dunlap, 
Gallup, and Gallup (1993, Figure 4) data set by subtracting the percentages of respondents who rated the quality of the local's environment as "very" or "fairly" bad from the percent- age ratings for the world's environment (explaining negative signs). Scores were reverse scored to have positive values, and average scores were then calculated for industrialized and developing countries.

\section{References}

Barone, M., Shimp, T., \& Sprott, D. (1997). Mere ownership revisited: A robust effect? Journal of Consumer Psychology, 6, 257-284.

Baumeister, R. F. (Ed.) (1999). The self in social psychology. Philadelphia, PA: Psychology Press.

Breakwell, G. M. (1993). Integrating paradigms:

Methodological implications. In

G. M. Breakwell \& D. Canter (Eds.), Empirical approaches

to social representations (pp. 180-200). Oxford, UK:

Clarendon Press.

Browne, M. W., \& Cudeck, R. (1993). Alternative ways of assessing model fit. In

K. A. Bollen \& J. S. Long (Eds.), Testing structural equation models (pp. 136-162). Beverly Hills, CA: Sage. Bunting, T. E., \& Cousins, L. R. (1985). Environmental dispositions among school- age children: A preliminary investigation. Environment and Behavior, 17, 725-768. Carmines, E. G., \& McIver, J. D. (1981). Analyzing models with unobserved variables: Analysis of covariance structures. In G. W. Bohinstedt \& E. F. Borgatta (Eds.),

Social measurement: Current issues (pp. 65-115). Beverly Hills, CA: Sage. 
Cohen, J. (1992). A power primer. Psychological Bulletin, 112, 155-159.

De Haven Smith, L. (1988). Environmental belief systems.

Environment and Behavior, 20, 276-299.

Dunlap, R., Gallup, G., \& Gallup, A. (1993). Of global

concern: Results of the health of the planet survey.

Environment, 35(7-15), 33-39.

Dunlap, R., Van Liere, K., Mertig, A., \& Jones, R. E. (2000).

Measuring endorsement of the New Ecological Paradigm: A

revised NEP scale. Journal of Social Issues, 56, 425-442.

Epley, N., \& Dunning, D. (2000). Feeling "holier than thou":

Are self-serving assessments produced by errors in self- or

social prediction. Journal of Personality and Social

Psychology, 79, 861-875.

Epley, N., \& Whitchurch, E. (2008). Mirror, mirror on the wall:

Enhancement in self- recognition. Personality and Social

Psychology Bulletin, 34, 1159-1170.

Fleury-Bahi, G. (2008). Environmental risk: Perception and target with local versus global evaluation. Psychological Reports, 102, 185-193.

Fransson, N., \& Gärling, T. (1999). Environmental concern:

Conceptual definitions, measurement methods, and research findings. Journal of Environmental Psychology, 19, 369382.

Fredrickson, B. L., \& Joiner, T. (2002). Positive emotions trigger upward spirals toward emotional well-being.

Psychological Science, 13, 172-175.

Gawronski, B., Bodenhausen, G., \& Becker, A. (2007). I like it, because I like myself: Associative self-anchoring and postdecisional change in implicit evaluations. Journal of Experimental Social Psychology, 43, 221-232. Gifford, R., Scannell, L., Kormos, C., Smolova, L., Biel, A., 
Boncu, S., . . . Uzzell, D. (2009). Temporal pessimism and spatial optimism in environmental assessments: An 18nation study. Journal of Environmental Psychology, 29, 112.

Hatfield, J., \& Job, R. F. S. (2001). Optimism bias about environmental degradation: The role of the range of impact of precautions. Journal of Environmental Psychology, 21, 17-30.

Hawcroft, L. J., \& Milfont, T. L. (2010). The use (and abuse) of the new environmental paradigm scale over the last 30 years: A meta-analysis. Journal of Environmental Psychology, 30, 143-158.

Hines, J. M., Hungerford, H. R., \& Tomera, A. N. (1986/1987). Analysis and synthesis of research on responsible environmental behavior: A meta-analysis. Journal of Environmental Education, 18, 1-8.

Hirt, E. R., Devers, E. E., \& McCrea, S. M. (2008). I want to be creative: Exploring the role of hedonic contingency theory in the positive mood-cognitive flexibility link. Journal of Personality and Social Psychology, 94, 214-230. Hofstede, G. (2001). Cultures consequence: Comparing values, behaviors, institutions, and organizations across nations. Thousand Oaks, CA: Sage.

Hu, L.-T., \& Bentler, P. M. (1999). Cutoff criteria for fit indexes in covariance structure analysis: Conventional criteria versus new alternatives. Structural Equation Modeling, 6, 1-55.

Hugh-Jones, S., \& Madill, A. (2009). “The air's got to be far cleaner here": A discursive analysis of place-identity threat. British Journal of Social Psychology, 48, 601-624. Inglehart, R. (1995). Public support for environmental protection: Objective problems and subjective values in 43 societies. PS: Political Science \& Politics, 15, 57-71. 
Jargowsky, P. A. (2005). Ecological fallacy. In K. KempfLeonard (Ed.), Encyclopedia of social measurement (Vol. 1, pp. 715-722). San Diego, CA: Academic Press. Jianguang, Z. (1994). Environmental hazards in the Chinese public's eyes. Risk Analysis, 14, 163-167.

Klein, C. T. F., \& Helweg-Larsen, M. (2002). Perceived control and the optimistic bias: A meta-analytic review. Psychology \& Health, 17, 437-446.

Leung, K., \& Bond, M. H. (2004). Social axioms: A model for social beliefs in multicultural perspective. Advances in Experimental Social Psychology, 36, 119-197. Liberman, N., \& Trope, Y. (2008). The psychology of transcending the here and now.

Science, 322, 1201-1205.

Lima, M. L., \& Castro, P. (2005). Cultural theory meets the community: Worldviews and local issues. Journal of Environmental Psychology, 25, 23-35.

Lord, C. G., Ross, L., \& Lepper, M. R. (1979). Biased assimilation and attitude polarization: The effects of prior theories on subsequently considered evidence. Journal of Personality and Social Psychology, 37, 2098-2109.

Luke, D. (2004). Multilevel modeling. Quantitative applications in the social sciences, 143. Thousand Oaks, CA: Sage.

Lyubomirsky, S., \& Lepper, H. (1999). A measure of subjective happiness: Preliminary reliability and construct validation. Social Indicators Research, 46, 137-155. Marques, J. F., Palma-Oliveira, J. M., Marques, J. F., \& Ferreira, M. B. (1995). Subgroup comparisons. In C. LevyLeboyer, M. Bonnes, K. Pawlik, J. Ferreira Marques, \& J. Chase (Eds.), The psychological and social determinants of environmental attitudes and behaviours: International comparison (pp. 148-181). Brussels, Belgium: EU Project 
Report.

Marsh, H. W. (1994). Confirmatory factor analysis models of factorial invariance: A multifaceted approach. Structural Equation Modeling, 1, 5-34.

Milfont, T. L. (2010). Global warming, climate change and human psychology. In V. Corral-Verdugo, C. H. GarcíaCadena, \& M. Frías-Arment (Eds.), Psychological approaches to sustainability: Current trends in theory, research and practice (pp. 19-42). New York, NY: Nova Science.

Milfont, T. L. (2012). Cultural differences in environmental engagement. In S. Clayton (Ed.). Handbook of environmental and conservation psychology Oxford, UK: Oxford University Press.

Milfont, T. L., Abrahamse, W., \& McCarthy, N. (2011). Spatial and temporal biases in assessments of environmental conditions in New Zealand. New Zealand Journal of Psychology, 40, 56-67.

Milfont, T. L., Duckitt, J., \& Cameron, L. D. (2006). A crosscultural study of envi- ronmental motive concerns and their implications for pro-environmental behav- iour.

Environment and Behavior, 38, 745-767.

Milfont, T. L., \& Fischer, R. (2010). Testing measurement invariance across groups: Applications in cross-cultural research. International Journal of Psychological Research, 3, 112-131.

Milfont, T. L., Sibley, C. G., \& Duckitt, J. (2010). Testing the moderating role of the components of norm activation on the relationship between values and environ- mental behaviour. Journal of Cross-Cultural Psychology, 41, 124131.

Murray, N., Sujan, H., Hirt, E. R., \& Sujan, M. (1990). The influence of mood on categorization-A cognitive flexibility interpretation. Journal of Personality and Social Psychology, 59, 411-425. 
Musson, C. (1974). Local attitudes to population growth in South Buckinghamshire. In

H. B. Perry (Ed.), Population and its problems: A plain man's guide (pp. 392-393). Oxford, UK: Clarendon Press.

Norenzayan, A., \& Heine, S. J. (2005). Psychological universals: What are they and how can we know? Psychological Bulletin, 131, 763-784.

Owe, E., Vignoles, V. L., Becker, M., Brown, R., Smith, P.B., Lee, S. W. S., . . Jalal, B. (2012). Contextualism as an important facet of individualism-collectivism: Person- hood beliefs across 37 national groups. Journal of Cross-Cultural Psychology, 44, 24-45.

Pahl, S., Harris, P. R., Todd, H. A., \& Rutter, D. R. (2005).

Comparative optimism for environmental risks. Journal of Environmental Psychology, 25, 1-11.

Palma-Oliveira, J. M. (2001). Ecological risk perception: The "Local Universal?" In

I. Linkov \& J. M. Palma-Oliveira (Eds.), Assessment and managing of environ- mental risk: Cost-efficient methods and applications (pp. 247-258). Amsterdam, Netherlands: NATO Science Series.

Palma-Oliveira, J. M., Nunes, L., \& Van der Kellen, D. (2009). Tão longe e tão perto: Percepção e distorção da distância na Área Metropolitana de Lisboa [So close yet so far: Distance perception and distortion in Lisbon urban area]. Communication presented at the 10th biannual Iberic meeting of Environmental Psychology, Lis- bon, Portugal.

Ponzetti, J. J., Jr. (2003). Growing old in rural communities: A visual methodology for studying place attachment. Journal of Rural Community Psychology, E6(1). Retrieved from http://www.marshall.edu/jrcp/E6one_Ponzetti.htm Rabinovich, A., Morton, T. A., Postmes, T., \& Verplanken, B. (2009). Think global, act local: The effect of goal and mindset specificity on willingness to donate to an 
environmental organization. Journal of Environmental Psychology, 29, 391-399.

Raudenbush, S., \& Bryk, A. (2002). Hierarchical linear models: Applications and data analysis methods (2nd ed.). Thousand Oaks, CA: Sage.

Schultz, P. W. (2001). Assessing the structure of environmental concern: Concern for self, other people, and the biosphere. Journal of Environmental Psychology, 21, 1-13.

Schultz, P. W. (2002). Environmental attitudes and behaviors across cultures. In

W. J. Lonner, D. L. Dinnel, S. A., Hayes, \& D. Sattler

(Eds.), Online readings in psychology and culture.

Bellingham: Western Washington University. Retrieved from http://www.wwu.edu/culture

Schultz, P. W., Gouveia, V., Cameron, L., Tankha, G., Schmuck, P., \& Franek, M. (2005). Values and their relationship to environmental concern and conservation behavior. Journal of Cross-Cultural Psychology, 36, 457475.

Schultz, P. W., \& Zelezny, L. (1999). Values as predictors of environmental attitudes: Evidence for consistency across 14 countries. Journal of Environmental Psychol- ogy, 19, 255265.

Smith, P. B., Peterson, M. F., Schwartz, S. H. (2002). Cultural values, sources of guid- ance and their relevance to managerial behaviors: A 47 nation study. Journal of CrossCultural Psychology, 33, 188-208.

Stern, P. C., \& Dietz, T. (1994). The value basis of environmental concern. Journal of Social Issues, 50, 65-84. Stern, P. C., Dietz, T., \& Kalof, L. (1993). Value orientations, gender, and environ- mental concern. Environment and Behavior, 25, 322-348.

Tamir, M., \& Robinson, M. D. (2007). The happy spotlight: 
Positive mood and selec- tive attention to rewarding information. Personality and Social Psychology Bul- letin, 33, 1124-1136.

Tremblay, K. R., \& Dunlap, R. E. (1978). Rural-urban residence and concern with environmental quality: A replication and extension. Rural Sociology, 43, 474-491. Trope, Y., \& Liberman, N. (2003). Temporal construal. Psychological Review, 110, 403-421.

Uzzell, D. L. (2000). The psycho-spatial dimension of global environmental prob- lems. Journal of Environmental Psychology, 20, 307-318.

Vandenberg, R. J., \& Lance, C. E. (2000). A review and synthesis of the measurement invariance literature: Suggestions, practices, and recommendations for organizational research. Organizational Research Methods, 3, 4-70. Van Liere, K. D., \& Dunlap, R. E. (1980). The social bases of environmental concern: A review of hypotheses, explanations and empirical evidence. Public Opinion Quarterly, 44, 181-197.

Weinstein, N. D. (1980). Unrealistic optimism about future life events. Journal of Personality and Social Psychology, 39, 806-820.

Weinstein, N. D. (1989). Optimistic biases about personal risks. Science, 246(4935), 1232-1233.

World Bank. (2008). Gross national product. Retrieved from http://siteresources.

worldbank.org/DATASTATISTICS/Resources/GNI.pdf World Database of Happiness. (2007/2008). Measure type:

122E 11-step numeral Life Satisfaction. Retrieved April 3, 2010, from http://worlddatabaseofhappiness.

eur.nl/hap_cor/desc_hind.php?ind=1491

World Values Survey. (2008). Survey data file. Available from 
http://www.worldval- uessurvey.org/

Yale Center for Environmental Law and Policy. (2005).

Environmental sustainability index: Benchmarking national environmental stewardship. Retrieved from http:// Yale (www.yale.edu/esi/ESI2005.pdf)

\section{Author Biographies}

P. Wesley Schultz is professor of psychology at California State University, San Marcos. He earned his bachelor's degree from the University of California, Irvine, and his doctoral degree from the Claremont Graduate University. His research inter- ests are in applied social psychology, particularly in the area of sustainable behavior. His current work focuses on social norms and the importance of social norms in promoting conservation.

Taciano L. Milfont is a senior lecturer and fellow at the Centre for Applied Cross- Cultural Research at Victoria University of Wellington, where he specializes in cross- cultural approaches to environmental issues. He earned his bachelor's and master's degrees from Brazilian universities, and his doctoral degree from the University of Auckland, New Zealand. His recent work has focused on environmental attitudes and behaviors, psychology of the Brazilian people, psychological time, and the develop- ment of a functional theory of human values.

Randie C. Chance is a doctoral student in the Department of Psychology at Southern Illinois University, Carbondale. She earned her bachelor's degree and master's degree from California State University, San Marcos. Her research interests are in applied social psychology and include motivation and cross-cultural and diversity issues, particularly as related to education and the workplace. 
Giuseppe Tronu earned his doctoral degree from the Sapienza University of Rome. His research interests are in general environmental attitudes and beliefs, personal norms, and their influence on sustainable behavior.

Sílvia Luís is an invited assistant professor at Évora University, Portugal. Her research interests are in applied social psychology and social cognition. Her current research focuses on social norms, particularly in normative knowledge activation, use, and relation with behavior.

Kaori Ando is associate professor at Nara Women's University, Japan. Her research interests are in environmental social psychology and cultural psychology, especially in comparing the antecedents of proenvironmental behavior across cultures.

Faiz Rasool is a graduate student in sociology at the University of Karachi, Pakistan. He received his masters in sociology from University of Karachi in 2009. His research interests are in environmental sociology, particularly in the area of everyday household environmental behaviors. His current work focuses on the influence of environmental values and attitudes on household environmental behaviors in Karachi.

Pamela Linera Roose is a graduate student at the Universidad Empresarial Siglo21, Córdoba, Argentina. She is completing her thesis in environmental psychology and she also runs a foundation (Fundación para el desarrollo de la responsabilidad social empresarial).

Charles Adedayo Ogunbode is a research associate in the Department of Wildlife and Ecotourism Management, 
University of Ibadan, Nigeria. He earned his bache- lor's degree in wildlife management at the University of Ibadan, and his current research interests are in conservation psychology, environmental education, and sustainable development.

Juana Castro is a graduate student in economics at the Universidad de Los Andes, Colombia. She is currently finishing her master's degree in economics at the same university, and her research is focused on the inclusion of environmental attitudes, values, and behavior interdependence as determinants of economic behavior toward environment.

Valdiney V. Gouveia is professor of social psychology at Federal University of Paraíba and senior researcher at National Council of Technological and Scientific Development, Brazil. He earned his bachelor's and master's degrees from Brazilian universities (Federal University of Paraíba and University of Brasília, respectively), and his doctoral degree from the Complutense University of Madrid, Spain. His research interests are in social psychology, particularly in the area of human values. His current work focuses on longitudinal change in values, value socialization, importance of values in promoting prosocial behaviors, and environmental concern. He and his colleagues are developing a functional theory of human values. 